\title{
STUDIES ON THE SUPERPLASTICITY EFFECT IN UFA: HISTORY AND DEVELOPMENT (in memory of Prof. O.A. Kaibyshev)
}

\author{
Ruslan Z. Valiev',2, Gennady A. Salishchev ${ }^{3}$, Farid Z. Utyashev ${ }^{4}$ \\ and Terence G. Langdon ${ }^{5}$ \\ 'Institute of Physics of Advanced Materials, Ufa State Aviation Technical University, K. Marx 12, \\ Ufa, 450008, Russia \\ ${ }^{2}$ Laboratory for Mechanics of Bulk Nanomaterials, Saint Petersburg State University, Saint Petersburg, Russia \\ ${ }^{3}$ Bulk Nanostructured Materials Laboratory, Department of Materials Science and Nanotechnology of Belgorod \\ State National Research University, Pobeda 85, 308015, Belgorod, Russia \\ ${ }^{4}$ Institute for Metals Superplasticity Problems, Russian Academy of Sciences, \\ Ufa. 450001 Bashkortostan, Russia \\ ${ }^{5}$ Materials Research Group, Department of Mechanical Engineering, University of Southampton, \\ Southampton SO17 1BJ, U.K.
}

Received: May 28, 2018

Abstract. Prof. O.A. Kaibyshev initiated studies on superplasticity of metals and alloys in Ufa in the 70s-80s of the last century. These studies gave momentum to the development of fundamental and applied studies on superplasticity not only in Russia but in numerous laboratories around the world. This paper highlights the major results of this early work and considers their state-ofthe-art and development perspectives for the science and practice of materials superplasticity.

\section{INTRODUCTION}

A tremendous development in studies on the superplasticity of metals and alloys in the 60 s and 80 s of the last century [1-4] gave impetus to the establishment of a number of specialized laboratories in this field in leading countries around the world. Prof. Oskar A. Kaibyshev started superplasticity studies in Ufa in 1969 after he had been assigned to a position as Head of Department at Ufa Aviation University (now Ufa State Aviation Technical University, USATU). Basic research and applied research laboratories for metals superplasticity were opened at the premises of the department. In 1980 a special design and technological bureau "Tantal" was established to develop technological processes. The significant success of these developments, presented by the team in a monograph [5], served at the conclusion of the Presidium of the Academy of Sciences of the USSR to establish the Institute for Metals Superplasticity Problems in Ufa in 1986. This was the first, and so far the only, institution devoted specifically to superplasticity throughout the world. Prof. O.A. Kaibyshev was assigned to a position of Director of the Institute from 1986 until 2005. The main research directions of the Institute are studies on the nature and mechanisms of the superplasticity effect, the formation of ultrafine-grained (UFG) structures and studies on superplasticity in commercial metals and alloys together with the development of technologies of practical use for this effect [6]. The

Corresponding author: R.Z. Valiev, e-mail: ruslan.valiev@ugatu.su

(c) 2018 Advanced Study Center Co. Ltd. 
studies were of fundamental and applied character and were based on close international collaborations $[7,8]$.

This paper is dedicated to the memory of Prof. O.A. Kaibyshev who passed away in June 02, 2017. The main results of his early work carried out in Ufa will be highlighted in brief and the state of the art of the studies and developments will then be discussed.

\section{NATURE AND MECHANISMS OF SUPERPLASTICITY}

The early reviews and books $[3,4,7-9,10,11]$ highlight several major events that arose in studies on the nature of superplasticity in the late 1970 s and the beginning of the 1980s. First, it became clear that superplasticity was the universal state of polycrystalline metal materials that originated when a fine-grained structure with a grain size of less than $10 \mu \mathrm{m}$ was formed therein and deformed at a certain temperature and over a certain range of strain rate (usually $T_{\text {def }}>0.5 \mathrm{Tm}, \dot{\varepsilon}=10^{-4}-10^{-3} \mathrm{~s}^{-1}$ ). Second, the superplastic flow was conditioned by the action of several known deformation mechanisms dislocation glide, grain boundary sliding and diffusion creep - but the determination of their contributions to the total deformation, and an identification of their role and interaction with each other, demonstrated the need for further studies. Therefore, the quantification of the contribution of different mechanisms in the total value of superplastic strain performed by Ufa researchers attracted much worldwide interest.

The studies showed that the main contribution close to $100 \%$ was made by grain boundary sliding, whereas dislocation glide and diffusion creep played an accommodating role (see $[6,7,12]$ ) and the grain boundary sliding was often cooperative. These conclusions are supported by texture research (see [7]) as well. It was also stated from special experiments on bicrystals and ultrafinegrained (UFG) materials that the interaction of lattice dislocations with grain boundaries could severely accelerate the grain boundary sliding due to the formation of so-called non-equilibrium boundaries which resulted from the introduction of extrinsic grain boundary dislocations formed during the dissociation of lattice dislocations. These pioneer results were published in a number of papers, and in 1987 a diploma on scientific discovery \#339 was issued [10]. Later, these findings found direct usage in comprehensive studies on superplasticity of UFG materials. In practice, it is known $[9,11]$ that
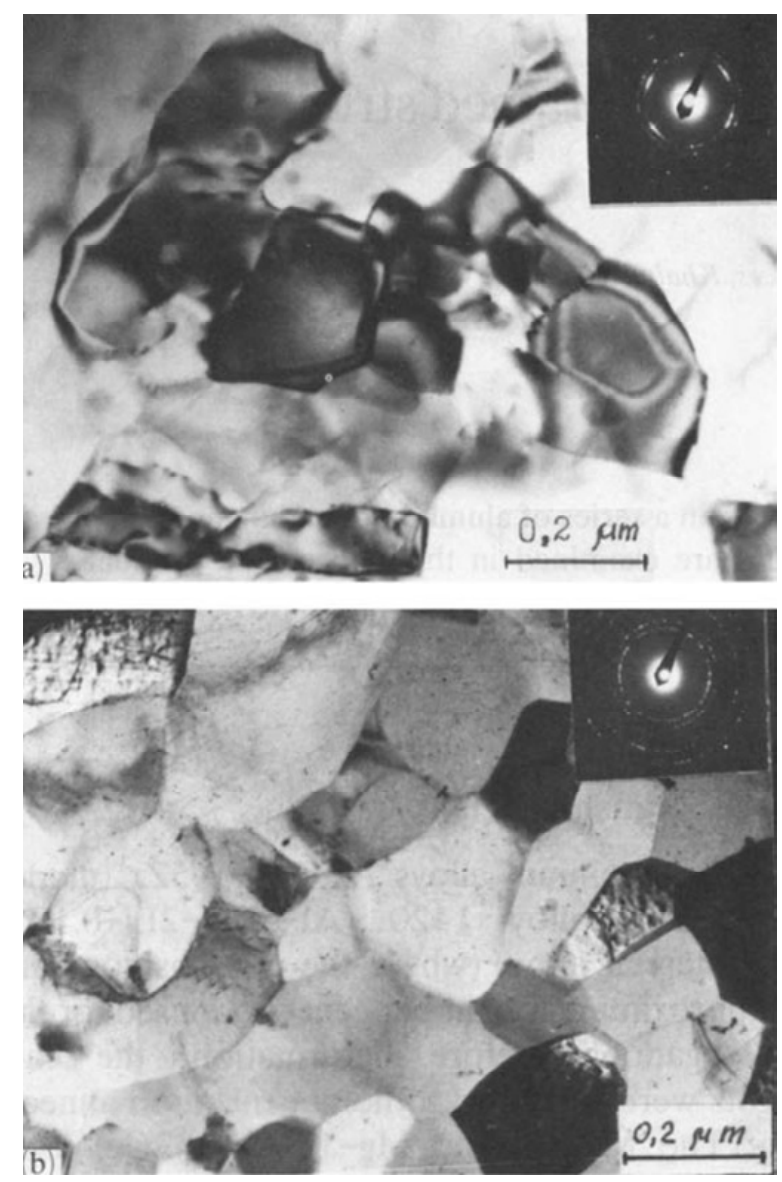

Fig. 1. TEM images and diffraction patterns of AlCu-Zr alloy: (a) after high pressure torsion, $n=5$; (b) after further annealing at $493 \mathrm{~K}$ for 1 hour.

the rate of superplastic strain can be presented by the relationship:

$\dot{\varepsilon}=\frac{A D G b}{K T}\left(\frac{b}{a}\right)^{p}\left(\frac{\sigma}{G}\right)^{n}$,

where $D$ - the diffusion coefficient, $G$ - the shear modulus, $b$ - the Burgers vector, $K$ - the Boltzmann constant, $T$ - the absolute temperature, $d$ - the grain size, $\sigma-$ the applied stress, $p$ and $n$ - exponents usually close to 2 , and $A$ - a dimensionless constant. It follows from Eq. (1) that a grain size reduction with all other parameters equal will be accompanied by a strain rate increase and temperature decrease. Superplasticity at higher strain rates for the first time was revealed in the materials processed by powder metallurgy techniques (see [11]).

Superplasticity at lower temperature was experimentally first observed in 1988 in Ufa and published in a paper [13] "Low-temperature superplasticity in metal materials". This new effect was discovered in an $\mathrm{Al}-4 \% \mathrm{Cu}-0.5 \% \mathrm{Zr}$ alloy when a UFG structure 

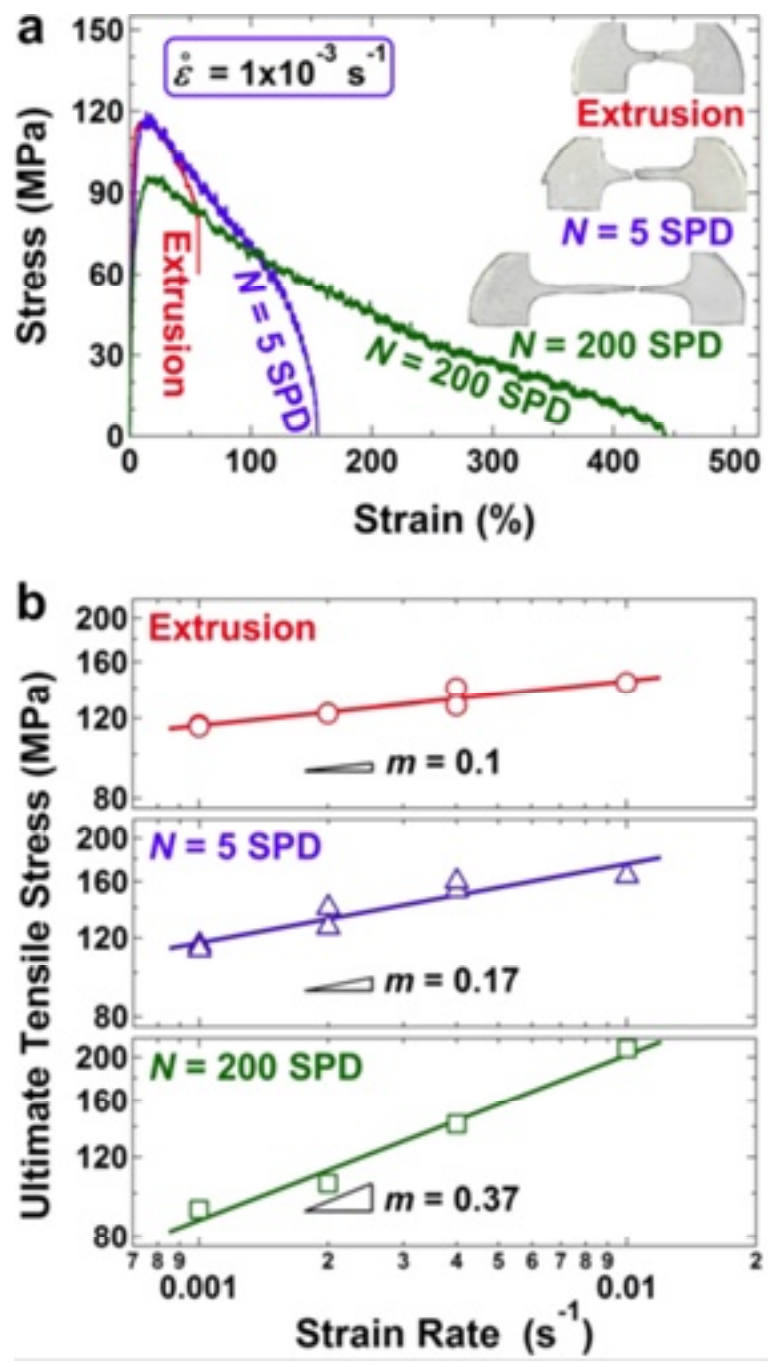

Fig. 2. Tensile plasticity and strain-rate sensitivity enhances after SPD processing in $\mathrm{Mg}-7 \% \mathrm{Li}$ alloy. Results of tensile tests performed at $300 \mathrm{~K}$ for the samples processed by extrusion and SPD for $N$ $=5$ and 200 cycles. (a) Stress-strain curves measured at a strain rate of $1 \times 10^{-3} \mathrm{~s}^{-1}$. Inset: appearance of tensile specimens after pulling to failure. (b) Ultimate tensile stress as a function of strain rate; the slopes represent the strain-rate sensitivity, $\mathrm{m}$. The sample after 200 SPD cycles exhibits roomtemperature superplasticity with $m=0.37$.

with a submicron grain size of $0.3 \mu \mathrm{m}$ (Fig. 1) was formed in it using the so-called severe plastic deformation (SPD) that included shear deformation under pressure. Later, the first international paper on UFG alloys produced by SPD processing was published in 1993 [14] (see Sections 2 and 3) and some time afterwards a first paper on high strain rate superplasticity $\left(\dot{\mathrm{E}}=10^{-2} \mathrm{~s}^{-1}\right)$ in Al alloys with UFG structure was published [15]. These and other publications on superplasticity of UFG materials $[16,17]$ have led to a substantial development of new re- search directions connected with studies on bulk nanostructured materials processed by SPD techniques [18] (www.nanospd.org). The main goal of the research on SPD was to produce nanostructured and ultrafine-grained materials, to study their irregular physical and mechanical properties and to investigate their potential applications.

Among recent papers on superplasticity of UFG materials produced by SPD techniques, it is important to single out research aimed at achievements of very high ductile properties in these materials even at room temperature. According to Eq. (1), very high ductile properties can be achieved by controlling not only the grain size but also the grain boundary properties. Indeed, the diffusion in grain boundaries can be enhanced by several orders due to control over the boundary structure and, in particular, due to certain grain boundary segregations $[19,20]$, and as a result grain boundary sliding may be activated even at room temperature. This was experimentally observed for the first time in an Al-30\% Zn alloy with UFG structure, in which an elongation of over $150 \%$ was achieved during tensile testing at room temperature [21]. Very recently a superplastic elongation of over $500 \%$ was obtained in a UFG Mg-7\% Li alloy during its deformation at room temperature [22] (Fig. 2). In the same work it was shown that $\mathrm{Li}$ segregations in the boundaries allow the activation of grain boundary sliding and ensure its considerable contribution at such low temperatures.

It is reasonable to assume that these recent findings on the nature of superplasticity of UFG materials will find wide practical applications in the creation of new techniques for the superplastic forming of items with complex shapes.

\section{SUPERPLASTICITY OF COMMERCIAL ALLOYS}

In early studies the interest to superplasticity of commercial alloys was conditioned by both the possibility of a significant enhancement in their processability and on obtaining new data on the peculiarities of the superplasticity effect as manifest due to different types of microstructure and some phase transformations [1-5]. The microstructures of most commercial alloys (excluding some Ti alloys) are coarse-grained and, therefore, in order to transform them into the superplastic state a preliminary treatment for microstructural refinement should be performed. In order to form a UFG microstructure, thermal treatment techniques based on the use of phase transformation peculiarities and deformation, and thermal treatments that imply different types of 


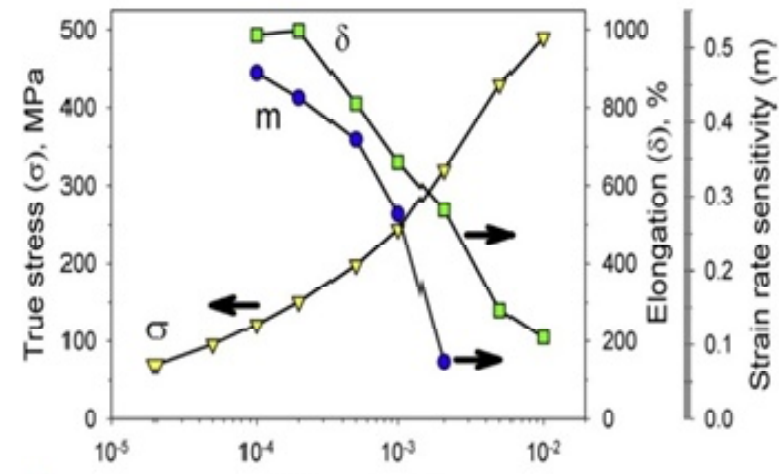

a

Strain rate, $\mathrm{s}^{-1}$

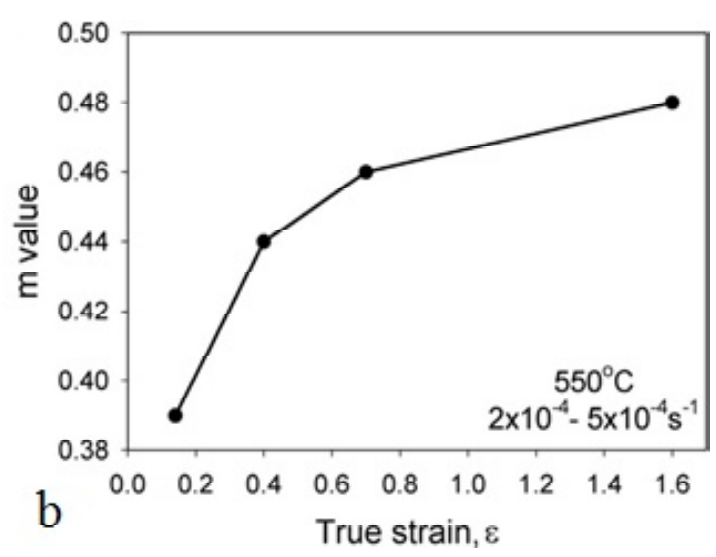

Fig. 3. Mechanical properties (a) and strain rate sensitivity coefficient $m$ vs true strain at $550^{\circ} \mathrm{C}$ in UFG Ti$6 \mathrm{Al}-4 \mathrm{~V}$ alloy. The stress was defined at $\varepsilon \sim 0.2$.

recrystallization, were used depending on the compositions of the alloys $[6,7,9,11]$. The latter has gained the highest development due to its universal nature. The successful application of conventional metal forming techniques such as forging, rolling or extrusion to produce a microstructure with a grain size of 1-15 $\mu \mathrm{m}$ was demonstrated $[5,6]$. In recent years, the development of new alloy compositions, the further development of SPD techniques and the possibilities for producing new structural states have provided a potential for obtaining new results in these superplasticity studies.

\subsection{Two-phase Ti alloys}

Two-phase $(\alpha+\beta)$ Ti alloys demonstrate the most impressive superplasticity values as compared to $\alpha$ or $\beta$ Ti alloys $[6,7]$. The wide industrial applications of $(\alpha+\beta)$ Ti-6Al-4V (VT6) alloy have led to intensive studies of its superplastic behavior [6-8,11,23-26]. Presently, different items for aircraft engineering are produced mainly from this alloy. Superplastic forming/diffusion welding and isothermal forging and rolling techniques are used in the conditions of superplastic temperature and rate $[8,27]$. Usually in two-phase $\mathrm{Ti}$ alloys the highest superplasticity values (relative elongation and strain rate sensitivity coefficient $m$ ) are observed in the upper part of the $(\alpha+\beta)$ zone when the ratio between these phases is close to 50/50. As was shown earlier [6,7], a grain size reduction and the formation of a favorable crystallographic texture significantly expanded the temperature and strain rate range of superplasticity. The formation of UFG structure by SPD techniques allowed the observation of low-temperature superplasticity in two-phase Ti alloys [28]. In Ti-6Al$4 \mathrm{~V}$ (VT6) alloy with an average size of grains (subgrains) of $\alpha$-phase and $\beta$-phase particles of
0.1-0.4 $\mu \mathrm{m}$ produced by multiaxial deformation, record values of superplasticity were achieved at a temperature of $550^{\circ} \mathrm{C}$ and strain rate of $2 \times 10^{-4} \mathrm{~s}^{-1}$ : relative elongation of $1000 \%$ and $m=0.48$ (Fig. 3, [29]). It should be noted that the volume fraction of the $\beta$-phase at this temperature was lower than $10 \%$. The coefficient of the strain rate sensitivity $m$ increased with increasing strain (Fig. 3b), although in the conditions of regular superplasticity the values were reduced due to grain growth $[6-8,11]$. The structure changes were also irregular: no porosity was observed in the samples, and the rate of dynamic coarsening of the grains was higher compared to the static annealing.

Such behavior of UFG Ti-6Al-4V alloy was explained by the behavior of a soft matrix $\beta$-phase which after multiaxial deformation was concentrated in triple junctions of the $\alpha$-phase grains, but during superplastic deformation it was redistributed as a thin net along the boundaries contributing to more rapid diffusion and the development of grain boundary sliding. This result supports the possibility of improvements of superplastic properties in alloys by controlling the grain boundary structure.

\subsection{Alloys of the $\mathrm{Zn}-\mathrm{Al}$ system}

The perspectives of practical use of $\mathrm{Zn}$-Al alloys are first of all connected with their excellent damping properties which are the highest in the state after superplastic treatment [30]. Superplastic Zn-22\%Al alloy with a volume ratio of $\alpha / \eta$ phases $50 / 50$ is considered as the most promising damping alloy. However, its ductility is reduced quite intensely at regular ambient temperatures compared to 200-250 ${ }^{\circ} \mathrm{C}$, at which it can achieve elongations of several thousand percents [6,8]. In [31] the Zn-22\%Al alloy was subjected to ECAP and then it showed fea- 
tures of high strain rate superplasticity at room temperature: the maximum elongation was $400 \%, m=$ 0.3 at $5 \times 10^{-2} \mathrm{~s}^{-1}$. When the strain rate was reduced, the ductility decreased significantly. It is interesting that in $\mathrm{Zn}-0.3 \% \mathrm{Al}$ [32] and $\mathrm{Zn}-5 \% \mathrm{Al}$ [33] alloys subjected to ECAP the ductility values at room temperature and at high strain rates ranked insignificantly below those of $\mathrm{Zn}-22 \% \mathrm{Al}$ and considerably exceeded those at lower temperatures and strain rates. In $\mathrm{Zn}-0.3 \% \mathrm{Al}$ a maximum elongation of $1000 \%$ was achieved at $10^{-4} \mathrm{~s}^{-1}$ and an elongation of $350 \%$ was obtained at a rate of $10^{-2} \mathrm{~s}^{-1}$. The average grain size of the $\alpha$ and $\eta$ phases was 110 and $540 \mathrm{~nm}$, respectively, and in $\mathrm{Zn}-22 \% \mathrm{Al}$ the average grain size of both phases was $200 \mathrm{~nm}$. These results, as well as the above considered data for Ti- $6 \mathrm{Al}-4 \mathrm{~V}$, show that at low testing temperatures the volume ratio of phases does not exert a determining impact on the character of superplastic flow as compared to regular high temperature superplasticity. The microstructure stability grows significantly at lower temperatures, which in turn contributes to the stabilization of the grain size during superplastic deformation. The results demonstrate the possibility of using ZnAl alloys with wider varieties of compositions as damping materials.

\subsection{Aluminum alloys}

First of all, good formability is required for those aluminum alloys which are applied in the aerospace industry. These alloys having high specific mechanical properties at room temperature display excellent strength and sufficient ductility. Their transition in the UFG state allows implementing both low-temperature [14] and high strain rate superplasticity [15]. For example, the alloy 5024 (Al-Mg-Sc-Zr) with a grain size of $0.7 \mu \mathrm{m}$ produced by ECAP and pinned by coherent nanoparticles of $\mathrm{Al}_{3}(\mathrm{Sc}, \mathrm{Zr})$ revealed an excellent ductility of $3300 \%$ at $450^{\circ} \mathrm{C}$ and a strain rate of $5.6 \times 10^{-1} \mathrm{~s}^{-1}$ [34]. At $175^{\circ} \mathrm{C}$ and a strain rate of $1.4 \times 10^{-4} \mathrm{~s}^{-1}$ a relative elongation of $365 \%$ was obtained and at $275^{\circ} \mathrm{C}$ and a rate of $5.6 \times 10^{-3} \mathrm{~s}^{-1}$ the elongation was $1200 \%$. Close results in studies of high strain rate superplasticity were obtained in research focused on 1421 (Al-Li-Mg-Sc-Zr) [35] and 7075 (Al-Zn-Mg-Cu) [36] alloys. It is known that high superplasticity values in these alloys are the result of the formation of equiaxed UFG highly misoriented structures with high-angle grain boundaries during SPD. The formation of such a structure and superplasticity values depend on the processing technique [36]. The SPD techniques are characterized by different temperatures and strain degrees and accordingly different acting stresses and, therefore, grains of different sizes form in the structure. The following grain sizes were obtained for different treatment types: $100 \mathrm{~nm}$ (HPT), $163 \mathrm{~nm}$ (ECAP), $244 \mathrm{~nm}$ (FSP) and $350 \mathrm{~nm}$ (ARB). However, the highest elongations of $550 \%$ at $300^{\circ} \mathrm{C}$ and $10^{-2} \mathrm{~s}^{-1}$ were obtained in the state after FSP. The authors explain this by noting that not only the grain size is important for the highest contribution of grain boundary sliding in deformation but also the value of the mean boundary misorientations which was a maximum in this state.

\subsection{Intermetallic alloys}

The intermetallic compounds of most interest include titanium aluminides that are known to have extraordinary features such as high specific strength, creep and corrosion resistance [37]. However, a low ductility limits their use for practical applications and the processing of intermetallics under high pressure is quite a laborious task at temperatures over 1000-1200 ${ }^{\circ} \mathrm{C}$ [37]. The superplasticity temperature may be significantly reduced by the formation of ultrafine states in the alloys using multi-axial deformation [7]. Low-temperature superplasticity was observed in alloys of $\alpha_{2}-\left(\mathrm{Ti}_{3} \mathrm{Al}\right)$ as well as $\gamma$ - (TiAl) phase [38]. Superplastic behavior was observed at $600-900{ }^{\circ} \mathrm{C}$ (0.47$0.66 \mathrm{Tm}$ ), which is about $200-400^{\circ} \mathrm{C}$ lower than for the alloys with conventional fine-grained microstructures. At the same time, the strain rate range of superplastic characteristics shifted towards high strain rates. It is important to note that with a decrease in grain size the porosity was reduced. Adding elements that inhibit diffusion to $\gamma$-alloys increases structural stability and superplasticity [39]. For example, the addition of niobium to the alloy Ti$45 \mathrm{Al}-8 \mathrm{Nb}-0.2 \mathrm{C}$ develops relative elongations of 770 $1342 \%$ at $850-1050{ }^{\circ} \mathrm{C}$ using strain rates of $10^{-4}-10^{-3} \mathrm{~s}^{-1}$.

Boron is added to $\gamma$ alloys for the formation of boride particles that considerably restrict the grain size in ingots [37] and this improves a number of mechanical properties and performance. In [40] the mechanical behavior of the cast alloy Ti-43.2Al-1.9V1.1 Nb-1.0Zr-0.2Gd-0.2B (grain size $20 \mu \mathrm{m}$ ) was studied in a wide range of deformation temperatures of $900-1250{ }^{\circ} \mathrm{C}$ and the alloy was shown to most clearly exhibit superplastic behavior only at 1100 ${ }^{\circ} \mathrm{C}$, the temperature that corresponds to the upper part of the $\alpha_{2}+\gamma$ region. Superplastic flow at such temperatures was accompanied by dynamic recrystallization and the alloy showed signs of high 


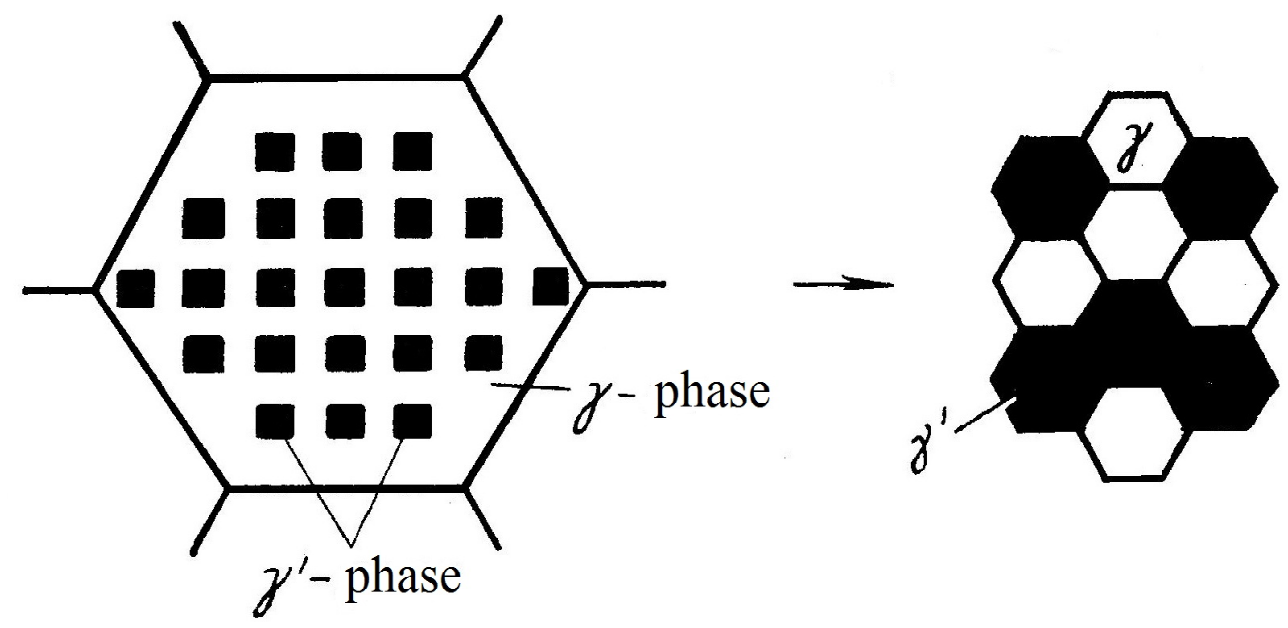

Fig. 4. Scheme illustrating the structure transformation in heat-resistant Ni-based alloys to transit them in the SP state.

strain rate superplasticity. Disordered $\alpha$ and $\beta$ phases were formed in the microstructure. Moreover, the $\beta$ phase was located along the boundaries of the $\alpha$ phase in the form of a thin interlayer with a volume fraction not exceeding $5 \%$. This result once again emphasizes that the mechanical behavior is significantly influenced by the second phase layer of a small volume fraction characterized by increased diffusion permeability.

\subsection{Heat-resistant Ni-based superalloys}

Heat-resistance is often considered as an antipode to superplasticity, as heat-resistant materials often possess an extremely low ductility and are characterized by high labor applied to metal forming which makes their practical use complicated. Thus, studies on superplasticity of heat-resistant Ni-based alloys (which are often called superalloys) initiated by O.A. Kaibyshev in the 70-80s of the last century $[6,7]$ has acquired a significant scientific and practical interest in recent decades.

As is well known, the main resistance to dislocation glide in $\mathrm{Ni}$-based superalloys is maintained by intermetallic particles of $\gamma^{\prime}$-phase $\left(\mathrm{Ni}_{3} \mathrm{Al}\right)$. A typical microstructure of $\mathrm{Ni}$-based superalloys ensuring their heat-resistance is characterized by homogeneous rather coarse grains $(\geq 30 \mu \mathrm{m}$ of the matrix) and a significant fraction ( $\geq 40-50 \%$ ) of disperse precipitates of $\gamma^{\prime}$-phase with a size of $500-100 \mathrm{~nm}$ which are coherently connected with the matrix (Fig. 4). The short-term strength of modern superalloys with such structures achieves $1500-1600 \mathrm{MPa}$, and the heat-resistance reaches $1000 \mathrm{MPa}$ over such a parameter as 100 -hour long-term strength at 750
${ }^{\circ} \mathrm{C}$ [41]. Furthermore, at this temperature and higher the ductile properties of superalloys are restricted by the values starting from several percents to a couple of tens percents during heating up to the solidus temperature, which complicates the technology of producing gas-turbine engine (GTE) parts. As studies show [6,7], in order to implement the superplasticity in these alloys it is necessary to transform the structure and form ultrafine grains (Fig. 4). Such a structure is necessary to ensure superplastic properties and, as a consequence, high workability in superalloys can be produced by several techniques. The first technique implies hot deformation on heavy horizontal presses [42]. As a result of pressing with high extrusion of ingots or powder billets, rods with a diameter of 200-300 mm with UFG structure of the microduplex type are produced.

The less energy-consuming technique for UFG structure formation in superalloys is based on fractional quasi-isothermal upsetting or forging. This technique is used to produce disks with a diameter of $300 \div 500 \mathrm{~mm}$ with UFG structure from coarsegrained hot-deformed billets [27]. There is experience in producing UFG disks from granular powder samples produced by hot isothermal pressing $[43,44]$.

Severe plastic deformation techniques have been used to produce UFG structures in superalloys. The SPD techniques allow implementing the conditions of low temperature or high strain rate superplasticity to produce items with complex shapes. In particular in [44] multiaxial deformation was applied to ATI Allvac 718Plus to produce a UFG structure with a grain size of $0.3 \mu \mathrm{m}$. A highest relative elongation of $1450 \%$ was obtained at $900{ }^{\circ} \mathrm{C}$ using a strain rate 
of $3 \times 10^{-4} \mathrm{~s}^{-1}$. A new technique of high-pressure sliding was introduced to refine the microstructure in the Inconel 718 alloy [45] where the technique allowed achieving a grain size of $120 \mathrm{~nm}$. The study of its superplastic properties enabled stating the possibility of observing high strain rate superplasticity: at $800^{\circ} \mathrm{C}$ and a strain rate of $\geq 10^{-2}$ $\mathrm{s}^{-1}$ where elongations of over $500 \%$ were obtained in the samples $[44,45]$. It is important to note that, with a grain size reduction, the superplastic properties in superalloys are exhibited at temperatures corresponding to the operating ones of $650-700^{\circ} \mathrm{C}$.

\subsection{Ceramics}

The use of superplasticity for ceramics processing is a challenging and promising task $[7,46]$ since such materials are inherently brittle with limited ductility even at temperatures above $1000^{\circ} \mathrm{C}$. Superplasticity has been observed in various types of ceramics: oxide ceramics $[7,46]$ and non-oxide ceramics such as silicon nitride $\left(\mathrm{Si}_{3} \mathrm{~N}_{4}\right)$ [47] and silicon carbide ( $\mathrm{SiC}$ ) [48]. A peculiar feature about ceramic materials is that the main deformation mechanism by GBS requires diffusion of atoms (ions) as a stress-relaxation process, whereas such diffusion is activated with high temperatures. Stress accommodation may be reduced with a decrease in grain size and thus the formation of the finest grain structure is particularly problematic for superplasticity and a decrease in temperature and/or an increase in the rate of its development. Other contributing and no less important factors are structural homogeneity, a decrease in the volume of residual defects, the suppression of dynamic grain growth and diffusion activation [49].

An analysis shows that a decrease in grain size of less than 100-200 nm and doping of ceramics for enhanced diffusion activity to reduce stresses in the area of triple junctions make it possible to observe high strain rate superplasticity at $1250-1300^{\circ} \mathrm{C}$, although conventionally it occurs at temperatures of $1400-1650{ }^{\circ} \mathrm{C}$ [11]. Another possible way for superplastic deformation is by applying a strong electric field above a threshold value [50]. It was shown that the application of a direct-current field of $190 \mathrm{~V} \cdot \mathrm{cm}^{-1}$ led to superplastic-like deformation in $\mathrm{Y}_{2} \mathrm{O}_{3}$-stabilized tetragonal $\mathrm{ZrO}_{2}$ ceramic material at $800^{\circ} \mathrm{C}$ and a strain rate of $2 \times 10^{-3} \mathrm{~s}^{-1}$ with a relative elongation of over $150 \%$. Low temperature superplasticity in ceramics was related to the acceleration of field-induced self-diffusion of oxygen cations.

\subsection{High-entropy alloys}

High-entropy alloys are a new class of materials containing five or more main elements with a concentration from 5 to 35 at.\% [51]. This name was given due to the much higher entropy of mixing as compared to conventional alloys, although there was no evidence of this effect in their structure [52]. Nevertheless, the alloys with such concentrations of elements were not studied before and possibilities of producing new structure states, and therefore unusual properties, attracted the attention of many researchers [52]. In these alloys, both homogeneous solid solutions and multiphase structures can be produced, where the latter demonstrates principally different high-temperature properties. Thus, CoCrFeNiMn [53] and CoCrFeNiMnTi0.1 [54] alloys were processed by HPT. The first alloy had a one-phase structure whereas the second alloy contained a small quantity of particles of the intermetallic phase. In the first alloy, a highest ductility of $500 \%$ was observed at $700^{\circ} \mathrm{C}$ using a strain rate of $1.0 \times$ $10^{-2} \mathrm{~s}^{-1}$, but in the second alloy in the same conditions the elongation was higher at $830 \%$. In an AlCoCrCuFeNi alloy [55] subjected to multiaxial deformation, the microstructure was more complex and consisted of four phases: three intermetallic phases with a close volume ratio of phases and a disordered sold solution based on copper as an intermediate layer. A relative elongation of $1240 \%$ was observed at $1000^{\circ} \mathrm{C}$ and a strain rate of $1.0 \times 10^{-2}$ $\mathrm{s}^{-1}$. Other authors [56] analyzed the experimental data on the superplasticity of high-entropy and regular alloys subjected to SPD and came to the conclusion that there was good agreement between the measured and predicted strain rates from the theoretical model [57].

These mentioned alloys do not exhaust the variety of crystalline materials exhibiting superplastic properties. The development of the studies performed by Prof. O.A. Kaibyshev with his colleagues on the superplasticity of different heat-resistant materials, including those based on intermetallic materials and ceramics, is of special importance at the present time [7]. Due to the large fraction of covalent bonds of atoms, these materials in the initial state differ in extremely low ductility, although they are very interesting for use in promising aircraft and rocket engineering. Heat-resistant Ni-based alloys are considered as an example of the use of such alloys in the superplastic state to produce parts and increase their structural properties. 

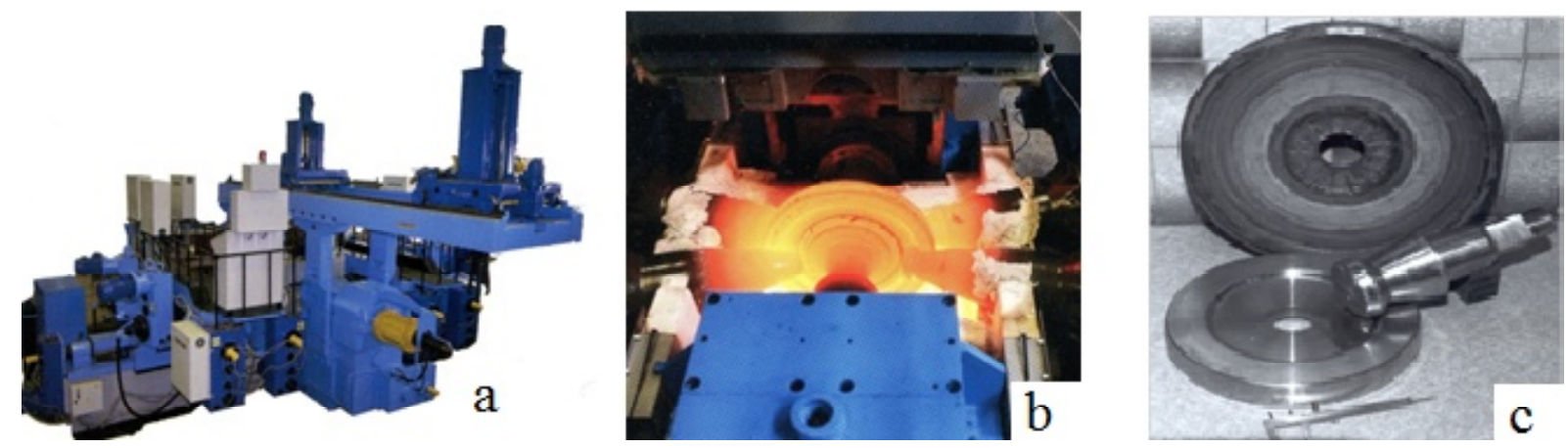

Fig. 5. External view of equipment (a), rolling in the isothermal chamber (b), initial sample. Rolling tool and disk (c), applied for rolling of GTE disks in the conditions of SPD.

\section{ADVANCED SUPERPLASTICITY- BASED TECHNIQUES}

High efficiency forming techniques were introduced as early as in the beginning of superplasticity research and included near net shape forging, forming and dieless drawing that remain relevant even today $[7,11,27]$. Low flow stresses, high plasticity, strong strain-rate sensitivity, uniformity of deformation - these are the superplasticity features that fundamentally distinguish the technique based on this phenomenon from conventional processing by pressure. Near net shape forging at temperature strain rate conditions of superplasticity were used for parts of jet-engine production from titanium and various superalloys that are hard to shape [27]. There are a few important advantages of this deformation method. Only small stresses occur in the workpiece and the grain size remains nearly unchanged. Another is the "near net shape" potential and the related savings in materials plus a greatly reduced need for subsequent machining. Normally a finegrained microstructure in the initial workpieces is needed. But in two-phase titanium alloys workpieces with initial lamellar coarse-grained microstructure can be taken, and its transformation into a globular one is fully at superplastic conditions [7]. Superplastic forging can be applied to such hardto-deform materials as intermetallides and ceramics also [58-60].

The temperature of forging can be strongly decreased by the formation of UFG microstructure in workpieces [7]. For example, forging of various items from the alloy Ti-6Al-4V with a UFG structure is possible at temperatures of $550-750{ }^{\circ} \mathrm{C}$ [61-63]. At the same time, strength and fatigue characteristics significantly exceed the properties of the alloy with conventional structure and plasticity, and toughness and heat resistance meet the required level $[63,64]$.
Low flow stresses and high elongations provide the possibility of making complex-shape objects by sheet stamping under superplasticity conditions $[11,27]$. The most complex products such as cellular panels or hollow blades are manufactured by gas superplastic forming combined with diffusion welding. As is shown in [65], a grain size reduction from 6-4 $\mu \mathrm{m}$ to $1 \mu \mathrm{m}$ in Ti-6Al-4V alloy sheets makes it possible to reduce the SPF/DB temperature from the conventional range of $900-920^{\circ} \mathrm{C}$ to $775^{\circ} \mathrm{C}$ and perform forming operations almost at the same stresses and ductility. The fabrication of sheets with UFG structure with a grain size of 0.1-0.4 mm allows for lowering the SPF/DB temperature to 600 ${ }^{\circ} \mathrm{C}$ [66]. Superplastic forming is also successfully used for products made from alloys based on titanium aluminides and ceramics $[11,67]$.

Dieless drawing developed as early as 1969 [68] has witnessed considerable development in recent years. The high sensitivity of the flow stress to the imposed strain rate in the process of superplasticity allows maintaining a uniformity of deformation during tension and thus the possibility of uniform thinning of the workpiece [69]. This technique is most efficiently applied to low-ductile and hard-deforming materials, such as magnesium alloys [70] and ceramics [71] and used for drawing both solid and tubular billets for applications in medicine and engineering. The ability of $\mathrm{Ti}$ and heat-resistant $\mathrm{Ni}$ alloys to significantly deform at low flow stresses in superplastic conditions has induced the development of an axisymmetric rolling process of gas turbine engine (GTE) components, such as disks, rings and hollow shafts $[27,72]$. Prof. O.A. Kaibyshev with colleagues patented these and a number of other developments. Figs. $5 a-5 c$ display examples of an automated bench, isothermal zone of deformation and a roller, by means of which the superplastic 
rolling of disks with diameters from $500 \mathrm{~mm}$ to 800 $\mathrm{mm}$ is performed.

\section{CONCLUSIONS}

The studies on superplasticity of ultrafine-grained materials performed in Ufa in the 70s-90s of the last century significantly impacted the development of this topic in Russia and in other countries. This paper considers the main results of these early studies on the nature and mechanisms of superplastic deformation, the peculiarities of its manifestation in commercial alloys and the further development in fundamental and applied research. The authors show in this report that the work of O.A. Kaibyshev remains in the focus of attention of modern researchers and will be helpful in future investigations of the theory and practice of the superplasticity effect.

\section{ACKNOWLEDGEMENTS}

This work was in part supported for RZV by the RF Ministry for Education and Science under Grant agreement No. 14.586.21.0061 (unique project identifier RFMEFI58618X0038). GAS gratefully acknowledges the financial support from the Russian Science Foundation (Grant No. 14-19-01104).

\section{REFERENCES}

[1] E.E Underwood // J. Metals. 14 (1962) 914.

[2] A.A. Presnyakov, Superplasticity of metals and alloys (Nauka, Alma-Ata, 1969).

[3] M.V. Grabskiy, Structure superplasticity of metals (Metallurgia, Moscow, 1975).

[4] J.W. Edington, K.N. Melton and C.P. Cutler // Prog. Mater. Sci. 21 (1976) 61.

[5] O.A. Kaibyshev, Ductility and superplasticity of metals (Metallurgia, Moscow, 1975).

[6] O.A. Kaibyshev, Superplasticity of commercial alloys (Moscow, Metallurgiya, 1984).

[7] O. A. Kaibyshev, Superplasticity of Alloys, Intermetallides and Ceramics (Springer-Verlag, Berlin, 1992).

[8] T.G. Langdon // J. Mater. Sci. 44 (2009) 5998.

[9] A.H. Chokshi, A.K. Mukherjee and T.G. Langdon // Mater. Sci. Eng. R10 (1993) 237.

[10] O.A. Kaibyshev and R.Z. Valiev, The phenomenon of formation of non-equlibrium grain boundaries when they absorb lattice dislocations, Bulletin Discoveries \& Inventions, \#7. Diploma number 339 (VNIIPI publ., Moscow, 1988).

[11] T.G. Nieh, J. Wadsworth and O.D. Sherby, Superplasticity in metals and ceramics
(Cambridge University Press, Cambridge, 1997).

[12] R.Z. Valiev and T.G. Langdon // Acta Metall. Mater. 41 (1993) 949.

[13] R.Z. Valiev, O.A. Kaibyshev, R.I. Kuznetsov, R.S. Musalimov and N.K. Tsenev // Doklady of AS USSR 301 (1988) 864.

[14] J. Wang, Z. Horita, M. Furukawa, M. Nemoto, N.K. Tsenev, R.Z. Valiev, Y. Ma and T.G. Langdon // J. Mater. Res. 8 (1993) 2810.

[15] R.Z. Valiev, D.A. Salimonenko, N.K. Tsenev, P.B. Berbon and T.G. Langdon // Scripta Mater. 37 (1997) 1945.

[16] R.B. Figueiredo and T.G. Langdon // $A d v$. Eng. Mater. 10 (2008) 37.

[17] M. Kawasaki and T.G. Langdon // Mater. Trans. 53 (2012) 87.

[18] R.Z. Valiev, A.P. Zhilyaev and T.G. Langdon, Bulk Nanostructural Materials (Wiley \& Sons Publ., Hoboken, NJ, 2014).

[19] Y.R. Kolobov, R.Z. Valiev, G.P. Grabovetskaya, et al., Grain boundary diffusion and properties of nanostructured materials (Nauka, Novosibirsk, 2001).

[20] X. Sauvage, A. Ganeev, Y. Ivanisenko, N. Enikeev, M. Murashkin and R. Valiev // Adv. Eng. Mater. 14 (2012) 968.

[21] R.Z. Valiev, M.Yu. Murashkin, A. Kilmametov, B. Straumal, N.Q. Chinh and T.G. Langdon // J Mater Sci. 45 (2010) 4718.

[22] K. Edalati, T. Masuda, M. Arita, M. Furui, X. Sauvage, Z. Horita and R.Z. Valiev // Scientific Reports 7: 2662 (2017) 1.

[23] H. Matsumoto, K. Yoshida, S.H. Lee, Y. Ono and A. Chiba // Mater. Lett. 98 (2013) 209.

[24] J. Fu, H. Ding, Y. Huang, P.H.R. Pereira, W.J. Zhang and T.G. Langdon // Lett. Mater. 5 (2015) 281.

[25] L.H. Wu, P. Xue, B.L. Xiao and Z.Y. Ma // Scripta Mater. 122 (2016) 26.

[26] H. Shahmir, F. Naghdi, P.H.R. Pereira, Y. Huang and T.G. Langdon // Mater. Sci. Eng. A718 (2018) 198.

[27] O.A. Kaibyshev and F.Z. Utyashev, Superplastisity: Microstructurial Refinement and Superplastic Roll Forming (Futurepast, Arlington, 2005).

[28] O.R. Valiakhmetov, R.M. Galeev and G.A. Salishchev // FMM 12 (1990) 204.

[29] S.V. Zherebtsov, E.A. Kudryavtsev, G.A. Salishchev, B.B. Straumal and S.L. Semiatin // Acta Materialia 121 (2016) 152. 
[30] T. Tanaka, K. Makii, A. Kushibe and K.Higashi // Mater. Trans. 43 (2002) 2449.

[31] M. Demirtas, G. Purcek, H. Yanar, Z.J. Zhang and Z.F. Zhang // Mater. Sci.Eng. A 620 (2015) 233.

[32] M. Demirtas, G. Purcek, H.Yanar, Z.J. Zhang and Z.F. Zhang // Mater. Sci. Eng. A 644 (2015) 17.

[33] M. Demirtas, G. Purcek, H. Yanar, Z.J. Zhang and Z.F. Zhang // J. Alloys Compds. 623 (2015) 213.

[34] D. Yuzbekova, A. Mogucheva and R. Kaibyshev // Mater. Sci. Eng. A 675 (2016) 228.

[35] R. Kaibyshev, D. Tagirov and A. Mogucheva // Adv. Eng. Mater. 12 (2010) 735.

[36] F. Carreno and O. A. Ruano // Mater. Sci. Forum. (2018), in press.

[37] F. Appel, J.D.H. Paul and M. Oehring, Gamma Titanium Aluminide Alloys: Science and Technology (Wiley, Weinheim, 2012).

[38] R.M. Imayev, G.A. Salishchev, O.N. Senkov, V.M. Imayev, M.R. Shagiev, N.K. Gabdullin, A.V. Kuznetsov and F.H. Froes // Mater. Sci. Eng. A 300 (2001) 263.

[39] V. Imayev, R. Gaisin, A. Rudskoy, T. Nazarova, R. Shaimardanov and R. Imayev // J. Alloys Compds. 663 (2016) 217.

[40] V.S. Sokolovsky, N.D. Stepanov, S.V. Zherebtsov, N.A. Nochovnaya, P.V. Panin, M.A. Zhilyakova, A.A. Popov and G.A. Salishchev // Intermetallics 94 (2018) 138.

[41] Y. Takizawa, T. Kajita, P. Kral, T. Masuda, K. Watanabe, M. Yumoto, Y. Otagiri, V. Sklenicka and Z. Horita // Mater. Sci. Eng. A682 (2017) 603.

[42] F.Z. Utyashev, M.I. Nagimov and S.K. Mukhtarov // Phys. Mech. Mater. 33 (2017) 152.

[43] R.V. Shakhov, M.I. Nagimov, S.K. Mukhtarov, F.Z. Utyashev, R.Y. Sukhorukov and A.A. Sidorov // Phys. Mech. Mater. 33 (2017) 171.

[44] Sh. Kh. Mukhtarov and F. Z. Utyashev // Mater. Sci. Forum. 838-839 (2016) 557.

[45] O.K. Fatkullin, V.I. Eremenko, O.N. Vlasova and N.M. Grits // Technology of Light Alloys 4-5 (2001) 149, In Russian.

[46] F. Wakai, S. Sakaguchi and Y. Matsuno // Adv. Mater. 1 (1986) 259.

[47] F. Wakai, Y. Kodama, S. Sakaguchi, N. Murayama, K. Izaki and K. Niihara // Nature 344 (1990) 421.
[48] Y. Shinoda, T. Nagano, H. Gu and F. Wakai // J. Am. Ceram. Soc. 82 (1999) 2916.

[49] K. Hiraga, B.-N. Kim, K. Morita, H. Yoshida, Y. Sakka and H. Huruse // J. Jpn. Soc. Powder Metall. 64 (2017) 515.

[50] H. Yoshida and Y. Sasaki // Scripta Mater. 146 (2018) 173.

[51] J.-W. Yeh, S.-K. Chen, S.-J. Lin, J.-Y. Gan, T.-S. Chin, T.-T. Shun, C.-H. Tsau and S.-Y. Chang // Adv. Eng. Mater. 6 (2004) 299.

[52] D.B. Miracle and O.N. Senkov // Acta Mater. 122 (2017) 448.

[53] H. Shahmir, J. He, Z. Lu, M. Kawasaki and T.G. Langdon // Mater. Sci. Eng. A 685 (2017) 342.

[54] H. Shahmir, M. Nili-Ahmadabadi, A. Shafie and T.G. Langdon // Mater. Sci. Eng. A 718 (2018) 468.

[55] D.G. Shaysultanov, N.D. Stepanov, A.V. Kuznetsov, G.A. Salishchev and O.N. Senkov // JOM65 (2013) 1815.

[56] H. Shahmir, M. Kawasaki and T. G Langdon // Mater. Sci. Eng. 194 (2017) 1.

[57] T.G. Langdon // Acta Metall. Mater. 42 (1994) 2437.

[58] G.A. Salishchev, R.M. Imaev, A.V. Kuznetsov, N.K. Gabdullin, G.A. Pavlov and V.I. Ivanov // Kuznechno-Shtampovochnoe Proizvodstvo 4 (1999) 23, In Russian.

[59] B.J. Kellett and F.F. Lange // J. Mater. Res. 3 (1988) 545.

[60] L.A. Akmoulin, M. Djahazi, N.D. Buravova and J.J. Jonas // Mater. Sci. Technol. 9 (1993) 26.

[61] S.V. Zherebtsov, R.M. Galeev, O.R. Valiakhmetov, S.P. Malysheva, G.A. Salishchev and M.M. Myshlyaev // Kuznechno-Shtampovochnoe Proizvodstvo 7 (1999) 17, In Russian.

[62] S. Zherebtsov and G. Salishchev // Mater. Sci. Forum 838 (2016) 294.

[63] R.Z. Valiev and I.P. Semenova // Mater. Sci. Forum 838-839 (2016) 23.

[64] G. Salishchev, S. Zherebtsov, S. Malysheva, A. Smyslov, E. Saphin and N. Izmaylova // Mater. Sci. Forum. 584-586 (2008) 783.

[65] L.D. Hefti // TMS Annual Meeting 1 (2010) 299.

[66] R.Y. Lutfullin, A.A. Kruglov, R.V. Safiullin, M.K. Mukhametrakhimov and O.A. Rudenko // Mater. Sci. Eng. A 503 (2009) 52. 
[67] R. Safiullin, R. Imayev, V. Imayev, W. Beck, F.H. Froes and G. Salishchev // Mater. Sci. Forum 551-552 (2007) 441.

[68] V. Weiss and R. Kot // Wire J. 9 (1969) 182.

[69] T. Furushima and K. Manabe // J. Mater. Process. Technol. 187-188 (2007) 236.

[70] A. Milenin, P. Kustra, D. Byrska-Wójcika and T. Furushima // Procedia Eng. 207 (2017) 2352.
[71] T. Furushima and K. Manabe // Manufact. Technol. 66 (2017) 265.

[72] N.P. Bewlay, M.F.X. Gigliotti, C.U. Hardwicke, O.A. Kaibyshev, F.Z. Utyashev and G.A. Salishchev // J. Mater. Process. Technol. 135 (2003) 324. 